\title{
Evaluating the use of informational technologies by students of healthcare colleges for academic purposes over a five-year period
}

\author{
Ali Azeez Al-Jumaili, et al. [full author details at the end of the article]
}

Received: 25 January 2021 / Accepted: 31 March 2021 / Published online: 9 April 2021

(C) The Author(s), under exclusive licence to Springer Science+Business Media, LLC, part of Springer Nature 2021

\begin{abstract}
This study aimed to assess the extent to which healthcare students use five informational technologies for daily academic purposes and to examine the changes in student perceptions toward these technologies over five years. This was a cross-sectional descriptive study in 10 different colleges in seven governorates. We conducted a survey using the instruments developed from the Technology Acceptance Model (TAM). The surveys were administered to convenience samples of students at the colleges of pharmacy, medicine, and dentistry in the participating universities. The survey was conducted three times over three different years: 2015, 2018, 2020. Five Information and Communication Technology components were included in the study: electronic course management (ECM), internet, computer, audio recording/commentary, and PowerPoint slides. The surveys were electronic and administered using Qualtrics Survey Software. For most respondents, the survey links were administered electronically via Facebook groups to convenience samples of students of the Bachelor programs. Kruskal-Wallis test was used to measure the difference among the three (years) surveys results. The multiple linear regression analysis was used to measure the associations between the five predictors of the TAM and the outcome variable (actual use of technology). There was a total of 3,113 valid surveys collected in 2015, 2018, and 2020. Nearly two thirds of participants were females. Most students did not have enough experience in using ECM before classes closure in March 2020. Lack of facilitating conditions and infrastructures like an expert technical support team and stable internet connections are negatively impacting students' acceptance of technology use in education. Moving from mainly face-to-face learning with partial electronic use in 2015 and 2018 to totally virtual learning in 2020 had a negative impact on the perceptions of healthcare college students of the five technologies across the five TAM domains (perceived usefulness, facilitating condition, ease of use, attitude toward use, intention to use) and the actual use of these technologies. The TAM successfully explained the factors influencing the actual use of technologies by healthcare college students. Continuing technical support and training can reduce students' electronic challenges. Technical status assessment needs to be done at the beginning, mid and end of the semester to evaluate the technical challenges facing students in online learning. The study
\end{abstract}


tools are internationally adoptable to evaluate the student perceptions of the ICT implementation for research and academic annual assessment purposes.

Keywords Informational technology $\cdot$ Healthcare colleges $\cdot$ Technology acceptance model $\cdot$ Electronic course management

\section{Introduction}

Information and communication technologies (ICTs) include any communication device or application, such as smartphones, tablets, computer, videos, distance learning, network hardware and software and others (Zare-ee, 2011). Currently there is an ever-expanding use of various technologies for academic purposes. As such, many studies examined perception, acceptance and satisfaction for students and faculty with various technologies and delivery method (Pawasauskas et al., 2014; Rodrigues et al., 2018; Venkatesh et al., 2020). ICT integration into education was found to be rewarding in terms of providing quick and convenient access to information, announcements, and class materials (Waycott et al., 2010). Additionally, it was reported to improve students' engagement in class and facilitate distance learning (Waycott et al., 2010). Faculty members in five different pharmacy schools in the USA believed incorporating different technologies into their teaching methods had positive impact on students learning and students agreed that the technologies they used met their academic needs (DiVall et al., 2013).

\subsection{Literature review}

In Iraq, administration efforts towards integrating e-learning into university education dates back to 2010 (Ameen et al., 2017); however, ICT use and implementation varied greatly depending on the administration of the university and the college (Alnuaimi, 2018; Khmiss \& Aaber, 2010). For instance, and until recently, university official email or other web-based systems have not been adopted in most Iraqi universities. Electronic course management (ECM) use in the most cases was the personal effort of instructors (Ahmed et al., 2020). ECM is part of the system services in e-learning that has been recently reported to be the most important dimension in the overall e-learning services (Pham et al., 2019). As such careful evaluation of the ECM component becomes essential to understand the status of e-learning especially in countries with recent experience in e-learning.

With the growing interest in incorporating technology into pedagogy, there have been expanding research aiming at examining different aspects of ICT implementation. Examples of areas examined included preparedness of students and/or faculty (Cutri et al., 2020; Martin et al., 2020; Parkes et al., 2015), satisfaction of students and/or faculty (Bolliger \& Wasilik, 2009; Choe et al., 2019), perception and acceptance of students and/or faculty of specific technology in education (Ustun et al., 2020; Y1lmaz, 2017). In settings with slow or recent ICT use in education, such studies become valuable in shaping strategies and action plans for ICT implementation. 
Iraqi universities are examples of such settings with young experience in distance education.

The level of ICT implementation in education in Iraq changed dramatically in early 2020 due to COIVD-19 pandemic. Campus closure forced many universities to transition to distance learning over short times. Such transition affected many universities around the globe. However, it was smooth for institutions with established infrastructures and prior experience with e-learning and challenging for others lacking adequate infrastructure and personnel training (Louise, 2020). Indeed, instructor training and transitional delivery methods were suggested pivotal for successful e-learning implementation (Fidalgo et al., 2020). During the year of 2020, research screening different aspects of COVID-19 impact on education escalated (ButlerHenderson et al., 2020). Case reports from a considerable number of institutions disclosed challenge and action steps taken in response to the pandemic (Bates et al., 2020).

Despite the immense scholarly work on different aspects of distance education, the change over time in students' attitude toward ICT implementation in academia is a largely unexplored area. This study investigates the changes in students' attitude over a five-year period. Additionally, the study looks at the impact of COVID-19 driven ICT implantation in education on students' acceptance of technology. The significance of this study stems from the relatively long period over which the study was conducted. To the best of our knowledge, this is the first study to report on the change in attitude over time for healthcare students in an environment of fresh ICT implementation. The study employs the Technology Acceptance Model (TAM) that has been extensively employed and validated for evaluating technology utilization in education (Granić \& Marangunić, 2019). The findings of this study, help identify influential action steps in distance education.

\subsection{Theoretical framework}

The Technology Acceptance Model (TAM) measures factors influencing the acceptance of new technology. The TAM has five main domains: Perceived usefulness (PU), perceived ease of use (PEU), attitude toward using (ATU), facilitating conditions (FC) and behavioral intention to use (BIU) in addition to the outcome variable (actual technology use-ACU) (Davis et al., 1989; Teo, 2011). Perceived usefulness may include the technology is helpful, effective and save time and efforts in the learning process. Perceived ease of use may refer that technology can be used easily by the students and does not need advanced skills. Attitude toward using may include preference and acceptance of a technology over others. Behavioral intention to use may include excitement and desire to use the technology soon. Actual technology use refers to the adoption/using of the technology in the daily learning process. All these five domains can influence on the actual use/acceptance of technology by users (Fig. 1). Basically, for any new learning technology to be accepted and used by students, they need to perceive that technology is useful in their learning process, easy to use and available/affordable in addition to have positive attitude toward this new technology. 


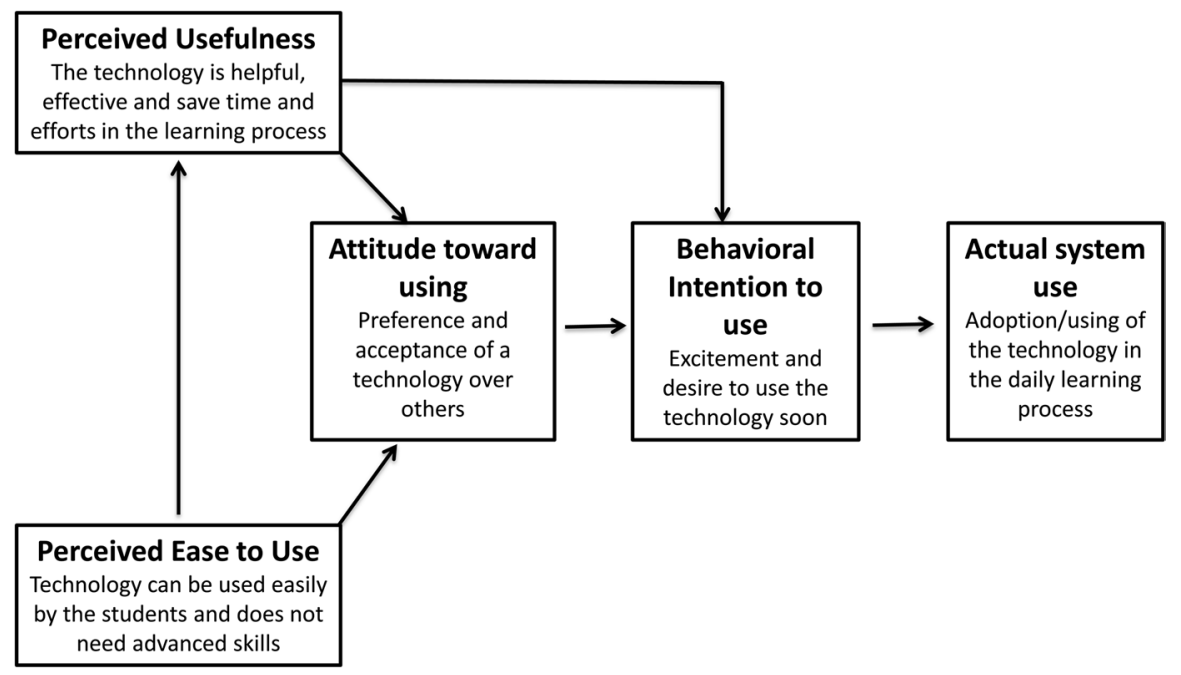

Fig. 1 Adopted Technology Acceptance Model (TAM)

\subsection{Objectives}

This study aimed to assess the extent to which Iraqi healthcare students use informational technology (ECM, internet, computer, PowerPoint slides, and recording lectures) for daily academic purposes and to examine the changes in student perceptions toward these technologies over five years.

\section{Methods}

This was a cross-sectional descriptive study in eight public universities and two private university colleges in seven different Iraqi governorates: Baghdad, Basrah, AlNajaf, Qadisiyah, Duhok, Erbil and Sulaimani. We conducted a survey using the instruments developed from the Technology Acceptance Model (TAM) (Al-Jumaili et al., 2017; Davis et al., 1989). The TAM has five predictive domains (perceived usefulness, perceived ease of use, facilitating conditions, attitude toward use, behavioral intention to use) which can influence the outcome variable (actual use of technology) (Davis et al., 1989; Teo, 2011) (Fig. 1). Five ICT components were included in the study: ECM, internet, computer, audio recording or commentary, and PowerPoint slides. The survey included questions about the five independent variables and the outcome variable for each of the five included technologies.

Some measures were adapted from previous studies (Akbulut, 2009; Al-Jumaili et al., 2017; Kazley et al., 2013; Waycott et al., 2010; Zare-ee, 2011) and others were newly developed. The surveys were administered to convenience samples of students at the colleges of pharmacy, medicine, and dentistry in the participating universities. Faculty at the participating institutions reviewed the instrument for face validity of 
constructs. The survey was conducted three times over three different years: 2015, 2018, 2020. In 2015, the survey was distributed from February 27, 2015 through May 25, 2015. In 2018, the survey was distributed from October through November. In 2020, the survey was distributed from April $4^{\text {th }}$ to April 20. A five-point Likert scale was used to answer the survey questionnaires (1-strongly disagree, 2-disagree, 3- neutral, 4-agree 5-strongly agree). The 2020 survey was distributed soon after transitioning to virtual classes (which occurred on March 17, 2020) due to COVID19 pandemic. The wording of some of the survey questions had to be modified in the 2020 survey to meet current technology use. specifically, the audio recording ICT component was modified to provide commentary.

Iraqi and American faculty members in colleges of pharmacy reviewed the survey questionnaire to avoid any biased and unclear questions. The survey questionnaires were pretested (pilot study) during November 2014 and 2020 to evaluate the reliability of new instruments. Faculty members of healthcare colleges included in the study (pharmacy, dentistry, medicine) teach and test academic courses in English. Hence, the questionnaires were in English. The surveys were electronic and administered using Qualtrics Survey Software (Qualtrics, Inc, Provo, UT). Every class at each college had its own students Facebook group to communicate for academic purposes. For most respondents, the survey links were administered electronically via Facebook groups (of each class) to convenience samples of students of the Bachelor programs $\left(2^{\text {nd }}, 3^{\text {rd }}, 4^{\text {th }}\right.$ and $5^{\text {th }}$-year students $)$ of included colleges. We excluded $1^{\text {st }}$ year students because of limited experience with using technology for academic purposes.

Personal characteristics were collected from the students such as age, gender, year of study, name of the university, and year of study. No incentives were offered. The survey was optional and anonymous. The study proposal received ethical permission from the ethical committees at the participating colleges.

\subsection{Statistical analyses}

The analyses were conducted using the Statistical Package for the Social Science (SPSS, version 22, IBM, New York, USA). Descriptive statistics (medians, frequencies and percentages) of the participants were calculated. Because the variables were not normally distributed, Kruskal-Wallis test was used to measure the difference among the three (years) surveys results. Kruskal Wallis Test (non-parametric) compares mean ranks, but they are usually large numbers and that is why we mentioned the median as well. For significant results, pairwise comparisons were used to identify between which years where the significant differences occurred. Spearman's correlation was used to measure the relationships between the outcome variables of the five technologies within each year. The multiple linear regression analysis was used to measure the associations between the five predictors of the TAM (usefulness of the technology, ease of use, facilitating conditions, attitude toward use, and behavioral intention to use) and the actual use of technology (outcome variable). Each variable in the model represented the summation of five variables of the same domain (of the five technologies) over the three years. This regression analysis 
tested whether the TAM could explain the factors influencing the actual use of the five technologies for academic purposes in the healthcare colleges.

\section{Results}

There was a total of 3,113 valid surveys collected of which 489 were in 2015, 731 in 2018 , and 1,893 in 2020 . Nearly two thirds of participants were females $(\approx 65 \%)$. Majority of participants were in the age range of 20-23 years across the different survey years of the study (Table 1). Higher participation was from Kufa University $(\mathrm{N}=264,54 \%)$ in 2015, Al- Kafeel University $(\mathrm{N}=224,30.6 \%)$ in 2018, and Basra University $(\mathrm{N}=697,36.8 \%)$ in 2020 . Pharmacy school students were the only participants in $2015(\mathrm{~N}=489)$ and they contributed about three quarters of participants $(\mathrm{N}=543,74.1 \%)$ in 2018 and $2020(\mathrm{~N}=1511,79.8 \%)$ (Table 1). Most participants were in the $4^{\text {th }}$ academic year in $2015(\mathrm{~N}=189,38.7 \%)$ and $2020(\mathrm{~N}=584,31.1 \%)$ while they were in the $3^{\text {rd }}$ academic year in $2018(\mathrm{~N}=256,35.1 \%)$ (Table 1$)$.

When asked about their use of ECM, $60.1 \%$ and $53.6 \%$ of responding students in 2018 and 2020 respectively stated they have used ECM at some point in their academic study. For the 2019-2020 academic year specifically, only $27.9 \%$ of responding students reported using ECM prior to campus closure due to the COVID-19 pandemic in March 2020. In 2015 and 2018, the median score showed 'agree' (4) for all six domains except for facilitating conditions where there was a 'neutral' median score (3). In 2020, the median score was 'neutral' (3) for all domains except for facilitating conditions and behavioral intention to use where the median score was 'disagreement' median score (2) (Table 2A).

The Kruskal-Wallis test followed by paired analysis showed significant differences in perceptions for all six domains toward ECM between results from 2015 and 2020 and those from 2018 and 2020. The differences between results from 2015 and 2018 were significant only in four domains and these are: perceived usefulness (ECM saves time and effort item), attitude toward use (ECM is really helpful item), behavioral intention to use, and actual use (Table 2A).

The student perceptions toward the internet component of ICT were similar to ECM. A median score of agree (4) was reported for actual use over the three years of study. The median scores of the internet component from 2015 and 2018 results were 'strongly agree' (5) for perceived usefulness in both years, 'neutral (3) for facilitating condition item (I have access to intent in the college) in both years and'agree' (4) for attitude toward use and behavioral intention to use (Table 2B). For facilitating condition items (I have internet at home), there was a strongly agreed median score (5) in the results from 2015. In contrast, the results shifted toward disagreement in 2020. In 2020, both facilitating condition items reported 'disagree' (2) for having internet in the college and 'strongly disagree' (1) for having internet at home (Table 2B). Perceived usefulness, attitude toward use, and behavioral intention to use showed a 'neutral' response (3) in 2020. Kruskal-Wallis tests followed by paired analysis showed significant differences between results from 2015 and 2020 and those from 2018 and 2020 for all internet domains (Table 2B). However, there was a non-significant difference between results from 2015 and 2018 except for the 
Table 1 The participating students' demographics

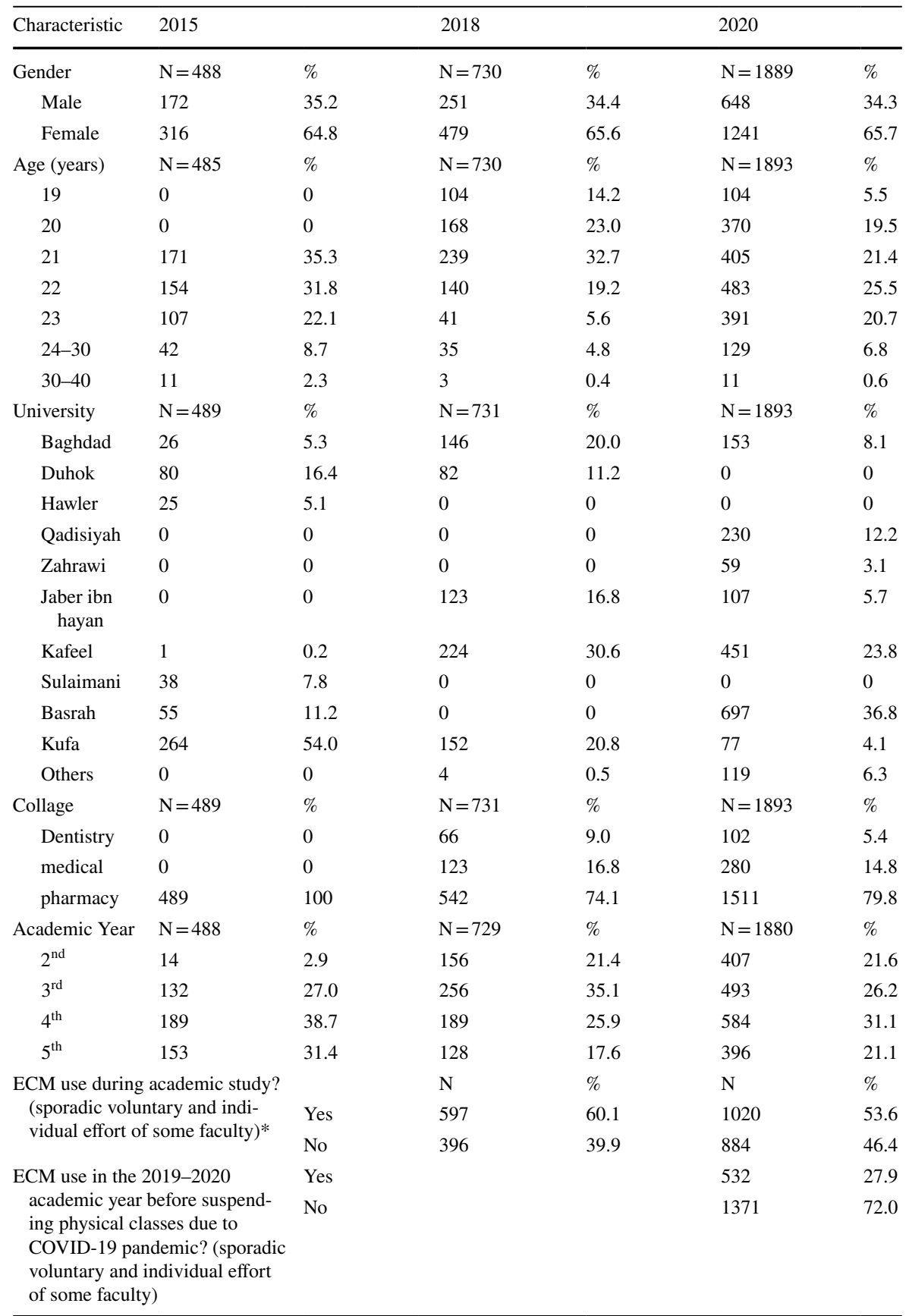

* Question was not included in the 2015 survey as ECM was not in use at time 
facilitating condition domain and one item of the behavioral intention to use domain (Table 2B).

In the computer component of ICT, there was a shift for the actual use domain from a median score 'agree' (4) in 2015 to 'neutral' (3) in 2018 and then to 'disagree' (2) in 2020. In 2015, the median score showed 'agree' (4) for perceived usefulness, ease of use, and behavioral intention to use. On the other hand, there was a 'neutral' median score (3) for facilitating conditions and attitude toward use for the 2015 results (Table 2C). In 2018, median scores were similar to those observed in 2015 across all domains except for actual use. In 2020, there was a 'neutral' median score (3) for all domains of the computer component of ICT except for facilitating conditions that had a 'strongly agree' score of 5 (Table 2C). Kruskal-Wallis tests followed by paired analysis showed significant differences in the results from 2015 and 2020, and 2018 and 2020 in all domains. For the results from 2015 and 2018, significant differences were observed for all domains except for facilitating condition and the attitude toward use domains (Table 2C).

For the PowerPoint slides component of ICT, actual use had a median score of agree (4) in 2015 and 2018 that changed to neutral (3) in 2020. Perceived usefulness, ease of use, attitude toward use, and behavioral intention to use had a median agree score (4) for the three time points of study. The median score for facilitating conditions was agree (4) in 2015 and 2018 and neutral (3) for the 2020 results (Table 2D). Kruskal-Wallis tests followed by paired analysis showed non-significant differences in results from 2018 and 2015 for all domains except for ease of use where differences were significant. The 2020 results were significantly different from those in 2015 and 2018 for all domains (Table 2D).

The last ICT component studied was audio recording/commentary. Actual use had a median agree score (4) in 2015 and 2018 that shifted to neutral (3) in 2020. Perceived usefulness items were significantly different across the three time points of the study, however, the median score for both items was 'agree' (4) across the three time points (Table 2E). Ease of use had a median 'agree' score (4) in results from 2015 and 2018 and a 'neutral' median score (3) in 2020. Kruskal-Wallis test followed by paired analysis for results in those two domains showed significant differences between 2015 and 2020 results, 2018 and 2020 results, but not between results from 2015 and 2018 (Table 2E). Facilitating conditions had median 'agree' score (4) for the years of 2015 and 2018. The attitude toward use domain had two items with an 'agree'median score (4) in 2015 and 2018. In 2020, one of the items had a 'neutral' median score (3) and the other had an 'agree' median score. For the item (audio recording/commentary is a great idea), there were non-significant differences in results from 2015 and 2020 (Table 2E).

The correlation analysis among the outcome variables (the actual use variables) of all five technologies showed a significant weak positive association between the actual use of all ICT in 2015 (Table 3). In 2018, there was a significant weak positive association between actual use of all ICT except for the association between audio recording and ECM which was nonsignificant and the association between actual use of ECM and internet which was significant moderate positive association (Table 3). Correlation analysis of the 2020 actual use variables of the different ICT components showed a significant moderate positive association between the use of PowerPoint slides and 


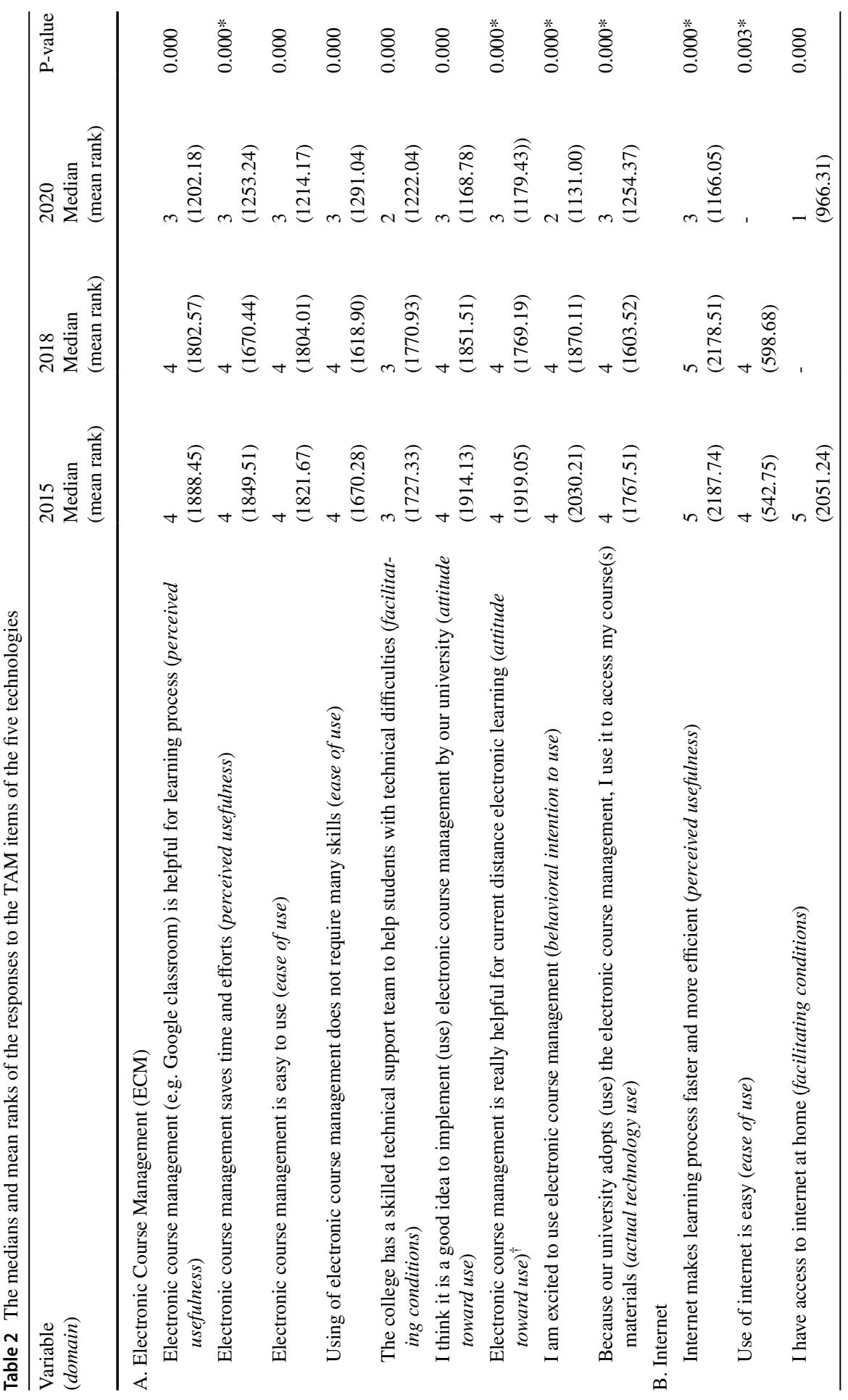




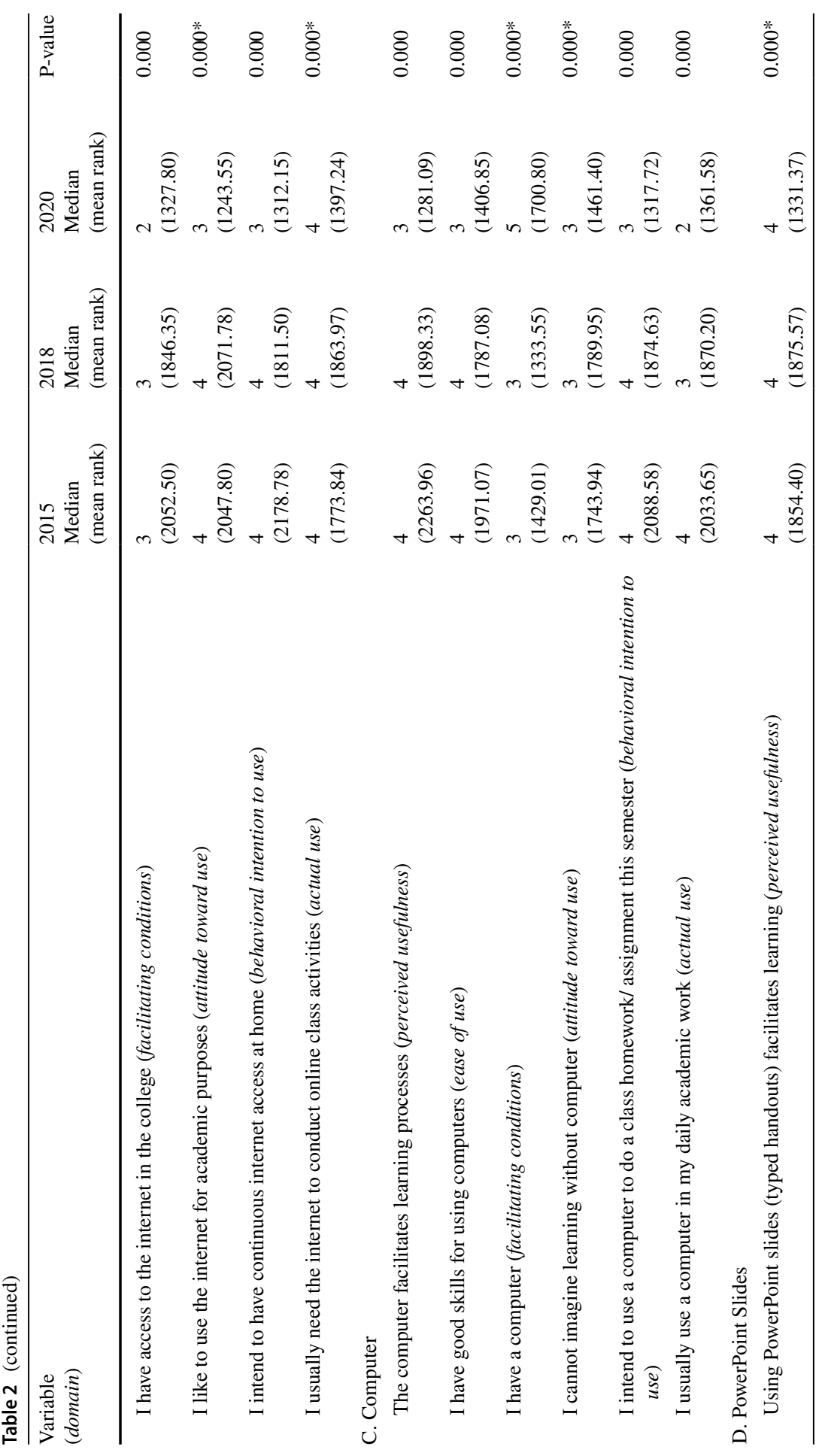




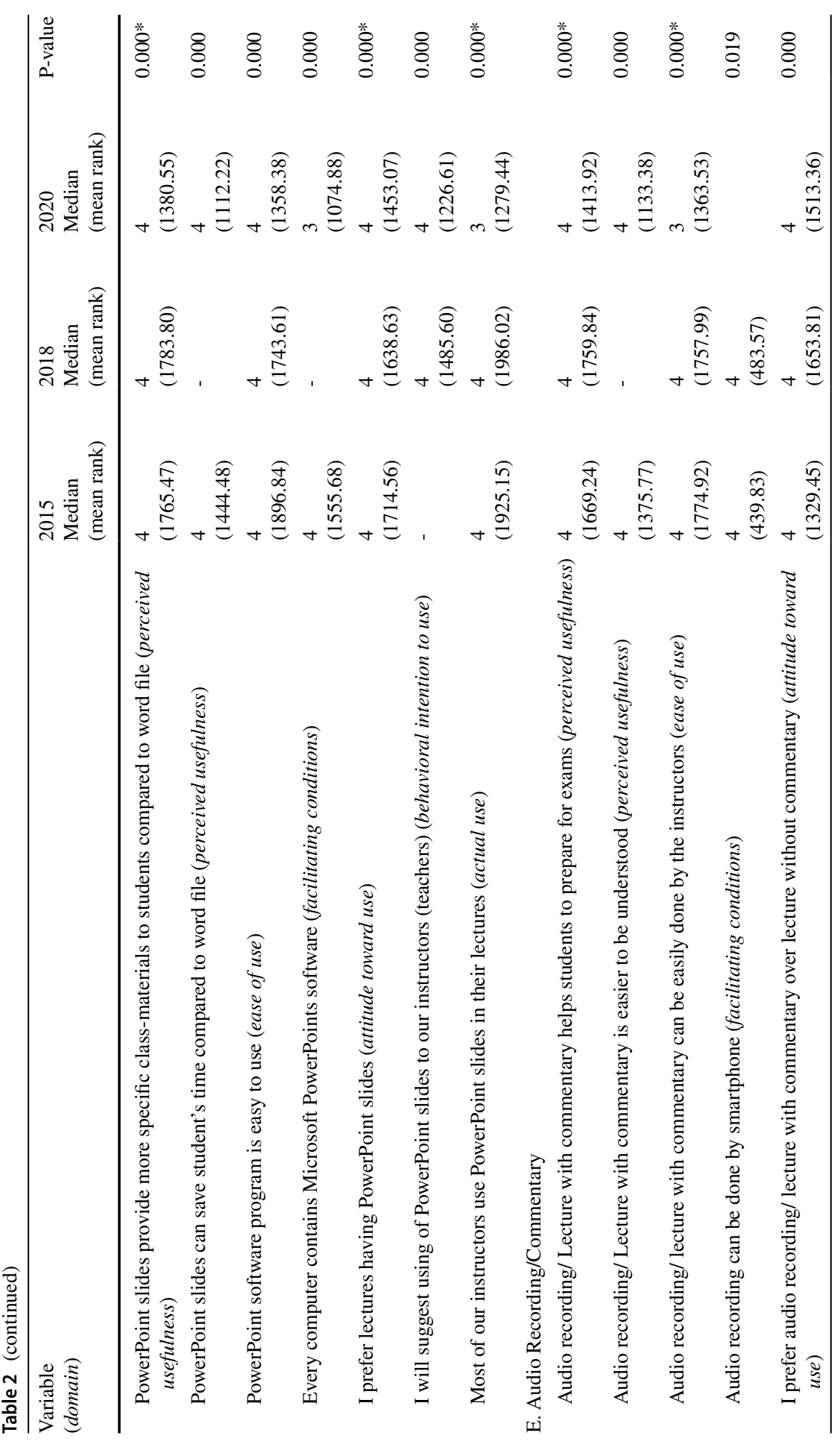




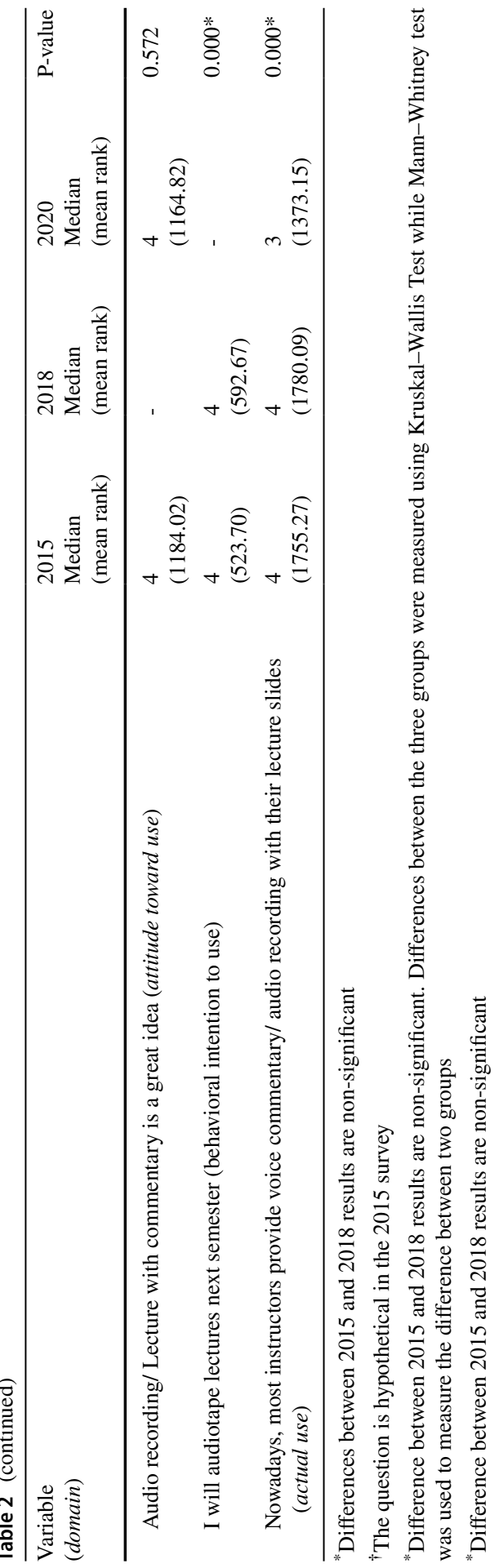


audio-lecture with commentary, PowerPoint slides and ECM, ECM and internet. For all other components, there was a significant weak positive association between their actual use for the 2020 results (Table 3).

According to the multiple linear regression analysis, the five predictors of the TAM (usefulness of the technology, ease of use, facilitating condition, attitude toward use, and behavioral intention to use) had significant ( $\mathrm{P}$-value $<0.05)$ positive associations with the outcome variable (actual use of the technology) (Table 4). The model explains $64.3 \%$ of the variance of the actual use of technology (which means this regression model has good fit for the observations). In summary, the regression analysis showed that the TAM successfully explained the factors influencing the actual use of technologies by healthcare college students.

\section{Discussion}

The implementation of various technologies in education has been in use by academic institutions and specifically integrated at the college level. In Iraqi universities and until recently, attempts at implementing different ICTs and E-learning were scarce and discrete (Al-Azawei et al., 2016; Al-Jumaili et al., 2017; Elameer \& Idrus, 2011; Khmiss \& Aaber, 2010). Additionally, most pilot attempts at introducing various technologies in pedagogy and the studies stemming from these attempts were directed to computer science colleges (Al-Azawei et al., 2017; Khmiss \& Aaber, 2010; Radif, 2016).

In this study, we compared technology acceptance by healthcare students for five important components of academic education, namely ECM, computer, internet, PowerPoint, and audio recording/lecture commentary across the years of 2015, 2018, and 2020. The study utilized the TAM to construct the survey and successfully predicted factors influencing the actual use of technologies by healthcare college students. Additionally, we performed correlation analyses to test the level of association between the outcome measures (actual use) for each technology for the three years of 2015, 2018 and 2020.

In 2015, all ICT components but ECM were implemented (Radif, 2016). In 2018, ECM was used as adjuvant to in-class lectures while in 2020 classes were solely administered and run through different ECM platforms. We observed a significant change of student attitude toward disagreement with the use of ECM in the year of 2020 compared to both 2015 and 2018. While it is expected that stress and anxiety associated with ongoing COVID-19 pandemic can have an impact in modulating students' responses (Al-Rabiaah et al., 2020; Odriozola-González et al., 2020), we believe that this is not the only reason behind reported findings. In 2018, students did not need to have good experience in using ECM and they were not dependent on it in their learning process as they were able to reach instructors in person to inquire about materials or turn in assignments. This was reflected in an agreeing attitude for perceived usefulness and ease of use in 2015 and 2018 that changed to a neutral attitude in 2020.

Moreover, the behavioral intention to use shifted significantly from agreement in 2015 and 2018 to disagreement in 2020 . These results can be in part due to lack of 
Table 3 The correlation among the outcome variables (actual use of ICT) of the five technologies within each year

\begin{tabular}{|c|c|c|c|c|c|}
\hline Item & & ECM & Internet & Computer & PowerPoint slides \\
\hline \multirow{3}{*}{$\begin{array}{l}\text { Use of Internet } \\
\rho \\
\text { P-value }\end{array}$} & 2015 & $\begin{array}{l}0.285 \\
0.000 *\end{array}$ & & & \\
\hline & 2018 & $\begin{array}{l}0.311 \\
0.000 *\end{array}$ & & & \\
\hline & 2020 & $\begin{array}{l}0.381 \\
0.000^{*}\end{array}$ & & & \\
\hline \multirow{3}{*}{$\begin{array}{l}\text { Use of Computer } \\
\rho \\
\text { P-value }\end{array}$} & 2015 & $\begin{array}{l}0.138 \\
0.002 *\end{array}$ & $\begin{array}{l}0.285 \\
0.000^{*}\end{array}$ & & \\
\hline & 2018 & $\begin{array}{l}0.259 \\
0.000 *\end{array}$ & $\begin{array}{l}0.288 \\
0.000^{*}\end{array}$ & & \\
\hline & 2020 & $\begin{array}{l}0.283 \\
0.000 *\end{array}$ & $\begin{array}{l}0.261 \\
0.000^{*}\end{array}$ & & \\
\hline \multirow{3}{*}{$\begin{array}{l}\text { Use of PowerPoint Slides } \\
\rho \\
\text { P-value }\end{array}$} & 2015 & $\begin{array}{l}0.145 \\
0.001 *\end{array}$ & $\begin{array}{l}0.188 \\
0.000 *\end{array}$ & $\begin{array}{l}0.133 \\
0.011 *\end{array}$ & \\
\hline & 2018 & $\begin{array}{l}0.136 \\
0.007 *\end{array}$ & $\begin{array}{l}0.233 \\
0.000 *\end{array}$ & $\begin{array}{l}0.176 \\
0.000 *\end{array}$ & \\
\hline & 2020 & $\begin{array}{l}0.323 \\
0.000^{*}\end{array}$ & $\begin{array}{l}0.265 \\
0.000^{*}\end{array}$ & $\begin{array}{l}0.240 \\
0.000 *\end{array}$ & \\
\hline \multirow{3}{*}{$\begin{array}{l}\text { Use of audio recording/ Commentary } \\
\rho \\
\text { P-value }\end{array}$} & 2015 & $\begin{array}{l}0.148 \\
0.001 *\end{array}$ & $\begin{array}{l}0.148 \\
0.001 *\end{array}$ & $\begin{array}{l}0.140 \\
0.002 *\end{array}$ & $\begin{array}{l}0.144 \\
0.001 *\end{array}$ \\
\hline & 2018 & $\begin{array}{l}0.058 \\
0.252\end{array}$ & $\begin{array}{l}0.111 \\
0.003 *\end{array}$ & $\begin{array}{l}0.142 \\
0.000 *\end{array}$ & $\begin{array}{l}0.170^{*} \\
0.000\end{array}$ \\
\hline & 2020 & $\begin{array}{l}0.289 \\
0.000 *\end{array}$ & $\begin{array}{l}0.272 \\
0.000^{*}\end{array}$ & $\begin{array}{l}0.163 \\
0.000^{*}\end{array}$ & $\begin{array}{l}0.336 \\
0.000^{*}\end{array}$ \\
\hline
\end{tabular}

${ }^{*}$ Significant according to Spearman correlation $(\mathrm{P}-\mathrm{value}<0.05)$. Spearman's $\rho=$ Spearman's rank correlation coefficient. ECM Electronic course management

adequate technical support and shortage of facilitating conditions as we observed consistently the lowest median for facilitating conditions compared to other model constructs for the three years of study $(2015,2018,2020)$. This comes in agreement with previously reported significant effect of resources availability on perceived ease of use and behavioral intention to use (Chen et al., 2013). It is worth noting that

Table 4 Multiple linear regression analysis of the five predictors of the Technology Acceptance Model influencing the actual use of technology

\begin{tabular}{lll}
\hline Model & $\begin{array}{l}\text { Standardized Coef- } \\
\text { ficients } \\
\text { Beta }\end{array}$ & P-value \\
\hline Sum Easy to use & 0.122 & \\
Sum Facilitating conditions & 0.158 & $0.000^{*}$ \\
Sum Attitude & 0.332 & $0.000^{*}$ \\
Sum Intention to use & 0.119 & $0.000^{*}$ \\
Sum usefulness & 0.191 & $0.000^{*}$ \\
\hline
\end{tabular}

R-square (coefficient of determination) $=0.643$ (the model explains $64.3 \%$ of the variance of the outcome variable (actual use of technology). Each variable in the model represents the summation of five variables (of five technologies) over the three years 
all colleges enrolled in this study had increased the availability of technical support teams post COVID-19. However, it is possible that the sudden campus-wide implementation of ECM coupled with limited experience of the technical support staff and the instructors with the use of ECM resulted in less-than-optimal services for the students. Consequently, students reported disagreement for the presence of facilitating conditions in 2020.

Additionally, in 2020 all courses were transitioned to distance learning which is fully dependent on ECM. This requires stable internet connections at a minimum (Al-Hariri \& Al-Hattami, 2015; Skinner et al., 2003) and preferably personal computers at home for a smooth learning process. Indeed, a study reported a significant relationship between internet access away from university and students' perception about ECM despite non-significant association between perception and actual use of ECM (Liyanagunawardena, 2008). In our study, there was a significant weak correlation between the internet domain and ECM in 2015 that changed to a significant moderate correlation in 2020.

Looking closely at the internet component across the three years, behavioral intention to use was significantly different in 2020 compared to 2015 and to 2018. Strikingly, perceived usefulness shifted from 'agree' in 2015 and 2018 to 'neutral' in 2020 despite increased students' dependence on the internet in their learning in 2020 compared to 2015 and 2018. On the other hand, there was a big shift from 'agree' in 2015 to disagree' in 2020 in regard to facilitating conditions at home (median 5 vs. 1). This was the biggest shift in attitude measured in any domain and across the five ICT components studied here which reflect lack of internet service at home for many students. Indeed, the quality of internet access was reported as a determinant of user's ability to perform internet-based tasks (Skinner et al., 2003). Additionally, speed and quality of internet service were reported to be among the determinants of students' acceptance and use of E-learning (Ameen et al., 2017). These findings support our belief that the observed trend of technology rejection in 2020 is underlined by lack of required facilitating conditions and most importantly the internet.

This trend of significant shift in attitude from'agree'/ 'neutral' in 2015 and 2018 to'neutral'/ 'disagree' in 2020 was evident in the computer component of ICT. Again, significant differences were observed in results from 2020 compared to 2015 and 2018, but not between 2015 and 2018 for most domains. Two domains are worth looking at for the computer component: having a computer (facilitating condition) and actual use of it. While more students reported having computers, fewer agreed with using them in their daily academic work. While it was expected to see a shift toward agreement for actual use in 2020, the results were the opposite and students disagreed with actual computer use. Expected shift toward agreement was hypothesized by the assumption that E-learning and online courses are better performed using computers as an important infrastructure (Ameen et al., 2017). The observed shift toward disagreement is possibly due to students' unfamiliarity with computer skills as demonstrated by a neutral attitude toward perceived ease of use in 2020 . Additionally, many students are expected to be accessing course materials from their smart phones using cellular data in situations with poor internet services (Ameen et al., 2017; Rashid et al., 2016). 
This trend of significant shifts in attitude from 'agree' in 2015 and 2018 to 'neutral' in 2020 was evident in the last two ICT components: PowerPoint slides and lecture recordings. These two components are believed to facilitate the learning process. This shift can be explained by the impact of sudden transition from in-class to E-learning format keeping in mind that college students are attentive to the delivery method (Cole \& Timmerman, 2015).

The component of lecture recording in 2015 and 2018 was in the format of student audio recording the lecture with instructor permission. The students would use the recordings to re-listen to the lecture after attending the in-class lecture. In 2020, this technology was replaced by instructor provided commentaries and video lectures due to class closure due to COVID-19 pandemic. The attitude toward using this component was the only domain that had a non-significantly different item between 2015 and 2020 which reflects students desire and preference of recorded lectures. Additionally, students generally agreed on the usefulness of recorded lectures across the three years of study. This agrees with previously reported findings on student preference of lecture capture as a facilitating tool in education (DiVall et al., 2013; Dommett et al., 2019). However, the median attitude toward actual use shifted from 'agree' in 2015 and 2018 (student lecture recording) to 'neutral' in 2020 (instructor provided commentary). This indicates that not all instructors provided video lectures or commentaries for their lectures in 2020 and some were providing class materials as handouts only. These results may reflect the limited technical skills of instructors especially if we considered that the survey was conducted in the beginning of the transition to virtual classes. Indeed, self-efficacy and ICT illiteracy were reported to hinder successful e-learning implementation (Al-Azawei et al., 2016).

Students in Iraq and other developing countries are facing many technical problems in online learning like instability of internet services at home, unavailability of a professional technical support team, and scarcity in using computers for academic purposes (Al-Azawei \& Lundqvist, 2015; Al-Azawei et al., 2016; Alnuaimi, 2018; Ameen et al., 2017). In this study, the five determinants of the conceptual framework used (TAM) were significantly associated with the actual use of technology by healthcare students. Since online education will continue for at least another academic year in Iraq (2020 - 2021) and many other countries with the high incidence rate of COVID-19 cases, efforts and expertise should be directed toward improving the educational process. The research model and results of this study supply university administrations with valuable strategic planning keys for implanting distance education. The study assesses the acceptance of E-learning by its end users, the students. and look into factors affecting their readiness to use of E-learning. The results of the study highlight important areas for where changes are needed. For example, a class material delivered over a live session only would be less helpful if not associated with recorded lectures due to poor internet connections. Continuing technical support and training can reduce electronic illiteracy among students. Technical assessment needs to be done at the mid-point and end of the semester to evaluate the technical challenges facing students in online learning. Once challenges are addressed, instructors and college administrations should work to resolve and overcome those challenges to the best possible to sustain the quality of education provided. 
The limitations of this study were mainly the difference in teaching delivery method between the years of 2015 and 2018 from one side and 2020 from the other side where earlier data were collected when educational materials were delivered in class and the use of technology was supportive to the education process. In contrast, in 2020 all education materials were delivered online. Additionally, it was not possible to follow up all institutions across the five years where four out of ten colleges included in the study participated for one year only. The study sample was mainly pharmacy colleges students with smaller proportions of dentistry and medical college students.

\section{Conclusions}

The perceptions of the healthcare students toward the use of ICT changed over time depending on the extent of ICT implementation by the academic institution. The relatively long timeframe of the study and the different levels of ICT implantation in education adds to the significance of the study. The study unveils the negative shift in student acceptance of technology use in education in response to higher ICT implementation. This response was driven by TAM domains namely, perceived usefulness, facilitating condition, ease of use, attitude toward use, and intention to use. Most students did not have enough experience in using ECM before classes closure in March 2020. Lack of facilitating conditions and infrastructures like an expert technical support team and stable internet connections are negatively impacting students' acceptance of technology use in education. Moving from mainly face-to-face learning with partial electronic use in 2015 and 2018 to totally virtual learning in 2020 had a negative impact on the perceptions of healthcare college students of the five technologies across the five TAM domains (perceived usefulness, facilitating condition, ease of use, attitude toward use, intention to use) and the outcome variable (actual use of these technologies). The TAM successfully explained the factors influencing the actual use of technologies by healthcare college students. Leveraged continuing technical support and training to reduce students' electronic challenges. Technical status assessment needs to be done at the beginning, mid and end of the semester to evaluate the technical challenges facing students in online learning. The study tools are internationally adoptable to evaluate the student perceptions of the ICT implementation for research and academic annual assessment purposes.

Acknowledgments The authors would like to thank the following faculty members at the participating Iraqi colleges of pharmacy to help us distribute the survey. Dr. Omer Q. B. Allela at University of Dohuk, Dr. Hiwa Saaed at University of Sulaimani, Dr. Alaadin Naqishbandi at Hawler University, Dr. Salem Ahjel at University of Al-Zahrawi and Dr. Dhia Jabbar at University of Baghdad.

Data availability The datasets used and/or analyzed during the current study are available from the corresponding author on reasonable request

Code availability Not applicable

\section{Declarations}

The survey was voluntary and anonymous, and the study proposal was approved by the Ethical Committee at University of Baghdad College of Pharmacy. 
All authors have contributed to this study and all authors reviewed and approved the final version of the manuscript. There are no conflicts of interest to disclose.

Ethical approval The Study proposal received ethical approval from the participating colleges.

Consent to participate All the participants were informed about the objectives of the study before taking the survey and the participation was voluntary and anonymous.

Consent for publication All authors agreed to submit this manuscript for publication.

Conflict of interest The authors declare no conflict of interest.

\section{References}

Ahmed, K. K., Salman, S. S., Abbas, W. A., Alkaisy, S. W., \& Kathem, S. H. (2020). Sudden transition of pharmacy education from traditional to distance learning in the era of COVID-19: Action steps of a leading pharmacy school in Iraq. Iraqi Journal of Pharmaceutical Sciences, 29(2), 271-278. https:// doi.org/10.31351/vol29iss2pp271-278.

Akbulut, Y. (2009). Students' Perceptions Of Change Readiness Of A Turkish Education Faculty Regarding Information And Communication Technologies. Turkish Online Journal of Distance Education (TOJDE), 10(1), 141-158.

Al-Azawei, A., \& Lundqvist, K. (2015). Learner differences in perceived satisfaction of an online learning: An extension to the technology acceptance model in an arabic sample. Electronic Journal of e-Learning, 13, 408-426.

Al-Azawei, A., Parslow, P., \& Lundqvist, K. (2016). Barriers and Opportunities of E-Learning Implementation in Iraq: A Case of Public Universities. The International Review of Research in Open and Distributed Learning, 17(5). https://doi.org/10.19173/irrodl.v17i5.2501.

Al-Azawei, A., Parslow, P., \& Lundqvist, K. (2017). Investigating the effect of learning styles in a blended e-learning system: An extension of the technology acceptance model (TAM). Australasian Journal of Educational Technology, 33(2). https://doi.org/10.14742/ajet.2741.

Al-Hariri, M. T., \& Al-Hattami, A. A. (2015). Utilization of internet by health colleges students at the University of Dammam. Journal of Taibah University Medical Sciences, 10(1), 66-73. https://doi. org/10.1016/j.jtumed.2015.01.006.

Al-Jumaili, A. A., Al-Rekabi, M. D., Alsawad, O. S., Allela, O. Q. B., Carnahan, R., Saaed, H., Naqishbandi, A., Kadhim, D. J., \& Sorofman, B. (2017). Exploring electronic communication modes between iraqi faculty and students of pharmacy schools using the technology acceptance model. American Journal of Pharmaceutical Education, 81(5), 89. https://doi.org/10.5688/ajpe81589.

Alnuaimi, A. S. (2018). Iraq. In A. S. Weber \& S. Hamlaoui (Eds.), E-Learning in the Middle East and North Africa (MENA) Region (pp. 123-138). Springer International Publishing. https://doi.org/10. 1007/978-3-319-68999-9_6.

Al-Rabiaah, A., Temsah, M. H., Al-Eyadhy, A. A., Hasan, G. M., Al-Zamil, F., Al-Subaie, S., Alsohime, F., Jamal, A., Alhaboob, A., Al-Saadi, B., \& Somily, A. M. (2020). Middle East Respiratory Syndrome-Corona Virus (MERS-CoV) associated stress among medical students at a university teaching hospital in Saudi Arabia. Journal of Infection and Public Health, 13(5), 687-691. https://doi. org/10.1016/j.jiph.2020.01.005.

Ameen, N., Willis, R., \& Abdullah, M. N. (2017). The use of e-learning by students in Iraqi universities: Potential and challenges 8th International Visible Conference on Educational Studies \& Applied Linguistics,

Bates, I., Rennie, T., \& Rennie, K. [Ed]. (2020). COVID-19 Special Collection [Special Issue]. Pharmacy Practice, 20(2), 117-309.

Bolliger, D. U., \& Wasilik, O. (2009). Factors influencing faculty satisfaction with online teaching and learning in higher education. Distance Education, 30(1), 103-116. https://doi.org/10.1080/01587 910902845949 . 
Butler-Henderson, K., Crawford, J., Rudolph, J., Lalani, K., \& Sabu, K. (2020). COVID-19 in Higher education literature database (CHELD V1): An open access systematic literature review database with coding rules. Journal of Applied Learning \& Teaching, 3(2), 1-6.

Chen, B., Sivo, S., Seilhamer, R., Sugar, A., \& Mao, J. (2013). User acceptance of mobile technology: A campus-wide implementation of blackboard's mobileTM learn application. Journal of Educational Computing Research, 49(3), 327-343. https://doi.org/10.2190/EC.49.3.c.

Choe, R. C., Scuric, Z., Eshkol, E., Cruser, S., Arndt, A., Cox, R., Toma, S. P., Shapiro, C., Levis-Fitzgerald, M., Barnes, G., \& Crosbie, R. H. (2019). Student satisfaction and learning outcomes in asynchronous online lecture videos. CBE_Life Sciences Education, 18(4), ar55. https://doi.org/10.1187/ cbe.18-08-0171.

Cole, A. W., \& Timmerman, E. C. (2015). What do current college students think about MOOCs? Journal of Online Learning \& Teaching, 11(2), 14. https://jolt.merlot.org/Vol11no2/Cole_0615.pdf. Accessed 21 April 2020.

Cutri, R. M., Mena, J., \& Whiting, E. F. (2020). Faculty readiness for online crisis teaching: Transitioning to online teaching during the COVID-19 pandemic. European Journal of Teacher Education, 43(4), 523-541. https://doi.org/10.1080/02619768.2020.1815702.

Davis, F. D., Bagozzi, R. P., \& Warshaw, P. R. (1989). User acceptance of computer technology: A comparison of two theoretical models. Management Science, 35(8), 982-1003. https://doi.org/10.1287/ mnsc.35.8.982.

DiVall, M. V., Hayney, M. S., Marsh, W., Neville, M. W., O’Barr, S., Sheets, E. D., \& Calhoun, L. D. (2013). Perceptions of pharmacy students, faculty members, and administrators on the use of technology in the classroom. American Journal of Pharmaceutical Education, 77(4), 75. https://doi.org/ 10.5688/ajpe77475.

Dommett, E. J., Gardner, B., \& van Tilburg, W. (2019). Staff and student views of lecture capture: A qualitative study. International Journal of Educational Technology in Higher Education, 16(1), 23. https://doi.org/10.1186/s41239-019-0153-2.

Elameer, A. S., \& Idrus, R. M. (2011). National E-learning Strategy to Enhance and Enrich the Iraqi Universities.

Fidalgo, P., Thormann, J., Kulyk, O., \& Lencastre, J. A. (2020). Students' perceptions on distance education: A multinational study. International Journal of Educational Technology in Higher Education, 17(1), 18. https://doi.org/10.1186/s41239-020-00194-2.

Granić, A., \& Marangunić, N. (2019). Technology acceptance model in educational context: A systematic literature review. British Journal of Educational Technology, 50. https://doi.org/10.1111/bjet.12864.

Kazley, A. S., Annan, D. L., Carson, N. E., Freeland, M., Hodge, A. B., Seif, G. A., \& Zoller, J. S. (2013). Understanding the use of educational technology among faculty, staff, and students at a medical university. TechTrends, 57(2), 63-70.

Khmiss, N. N., \& Aaber, Z. (2010). Building of reliable e-learning management system for Iraqi University campus. International Journal of Advancements in Computing Technology, 1. https://doi.org/10. 4156/ijact.vol1.issue2.8.

Liyanagunawardena, T. (2008). Measuring student perception and actual usage of online learning management system. Communications of the IBIMA, 4, 165-168.

Louise, B. L. (2020). The immediate global impact of COVID-19 on higher education institutions and workforce development. Pharmacy Education, 20(2), 2. https://doi.org/10.46542/pe.2020.202.12.

Martin, F., Stamper, B., \& Flowers, C. (2020). Examining student perception of readiness for online learning: Importance and confidence [Student Readiness, Online Learning, Student Attitude, Student Ability, Student Perception]. 2020, 24(2). https://doi.org/10.24059/olj.v24i2.2053.

Odriozola-González, P., Planchuelo-Gómez, Á., Irurtia, M. J., \& de Luis-García, R. (2020). Psychological effects of the COVID-19 outbreak and lockdown among students and workers of a Spanish university. Psychiatry Research, 290, 113108. https://doi.org/10.1016/j.psychres.2020.113108.

Parkes, M., Stein, S., \& Reading, C. (2015). Student preparedness for university e-learning environments. The Internet and Higher Education, 25(1), 10. https://doi.org/10.1016/j.iheduc.2014.10.002.

Pawasauskas, J., Matson, K. L., \& Youssef, R. (2014). Transitioning to computer-based testing. Currents in Pharmacy Teaching and Learning, 6(2), 289-297. https://doi.org/10.1016/j.cptl.2013.11.016.

Pham, L., Limbu, Y. B., Bui, T. K., Nguyen, H. T., \& Pham, H. T. (2019). Does e-learning service quality influence e-learning student satisfaction and loyalty? Evidence from Vietnam. International Journal of Educational Technology in Higher Education, 16(1), 7. https://doi.org/10.1186/ s41239-019-0136-3. 
Radif, M. I.-S. F. P. M. (2016). Employment Technology Acceptance Model (TAM) to adopt Learning Management System (LMS) In Iraqi Universities. 10th international technology, education and development conference, Valencia, Spain.

Rashid, B., Faraj, A., \& Shareef, T. (2016). Investigating and evaluating internet usage in Kurdistan region of Iraq. International Journal of Multidisciplinary and Current Research, 4, 474-479.

Rodrigues, M. W., Isotani, S., \& Zárate, L. E. (2018). Educational data mining: A review of evaluation process in the e-learning. Telematics and Informatics, 35(6), 1701-1717. https://doi.org/10.1016/j. tele.2018.04.015.

Skinner, H., Biscope, S., \& Poland, B. (2003). Quality of internet access: Barrier behind internet use statistics. Social Science and Medicine, 57(5), 875-880. https://doi.org/10.1016/S0277-9536(02) 00455-0.

Teo, T. (2011). Factors influencing teachers' intention to use technology: Model development and test. Computers \& Education, 57(4), 2432-2440. https://doi.org/10.1016/j.compedu.2011.06.008.

Ustun, A., Yılmaz, R., \& Karaoğlan Yilmaz, F. G. (2020). Virtual Reality in Medical Education. In (pp. 56-73). https://doi.org/10.4018/978-1-7998-2521-0.ch004.

Venkatesh, S., Rao, Y. K., Nagaraja, H., Woolley, T., Alele, F. O., \& Malau-Aduli, B. S. (2020). Factors influencing medical students' experiences and satisfaction with blended integrated e-learning. Medical Principles and Practice, 29(4), 396-402. https://doi.org/10.1159/000505210.

Waycott, J., Bennett, S., Kennedy, G., Dalgarno, B., \& Gray, K. (2010). Digital divides? Student and staff perceptions of information and communication technologies. Computers \& Education, 54(4), 1202-1211. https://doi.org/10.1016/j.compedu.2009.11.006.

Y1lmaz, R. (2017). Problems experienced in evaluating success and performance in distance education: A case study (Uzaktan Eğitimde Başarı ve Performansın Değerlendirilmesinde Karşılaşılan Sorunlar: Bir Durum Çalışması). Turkish Online Journal of Distance Education, 18, 39-51. https://doi.org/10. 17718/tojde.285713.

Zare-ee, A. (2011). University teachers' views on the use of information communication technologies in teaching and research. Turkish Online Joursnal of Educational Technology-TOJET, 10(3), 318-327.

Publisher's note Springer Nature remains neutral with regard to jurisdictional claims in published maps and institutional affiliations.

\title{
Authors and Affiliations
}

\section{Ali Azeez Al-Jumaili, ${ }^{1, D} \cdot$ Kawther K. Ahmed ${ }^{1,2}$ (D) \\ Ahmed Kadhim Al-Jalehawi ${ }^{3}$. Bashar G. Al-Fatlawi ${ }^{4}$. \\ Mohammed D. Al-Rekabi ${ }^{3}$. Oday Sajjad Al-Sawad ${ }^{5}$. Falah Hasan Shari ${ }^{5}$. Bernard Sorofman ${ }^{2}$}

\author{
Ali Azeez Al-Jumaili \\ ali.baraak@copharm.uobaghdad.edu.iq; Aliazeezali-aljumaili@uiowa.edu \\ Kawther K. Ahmed \\ kawthar.joudi@copharm.uobaghdad.edu.iq; Kawther-ahmed@uiowa.edu
}

Ahmed Kadhim Al-Jalehawi

Ahmad.k.pharm@Alkafeel.edu.iq

Bashar G. Al-Fatlawi

bashar.dr79@gmail.com

Mohammed D. Al-Rekabi

drmdr19761982@gmail.com

Oday Sajjad Al-Sawad

oday.azeez@uobasrah.edu.iq 
Falah Hasan Shari

falah.shary@uobasrah.edu.iq

Bernard Sorofman

Bernard-sorofman@uiowa.edu

1 University of Baghdad College of Pharmacy, Baghdad, Iraq

2 University of Iowa College of Pharmacy, Iowa, IA, USA

3 University of AlKafeel College of Pharmacy, Al-Najaf, Iraq

4 Center of Training and Development, Al-Diwaniyah Health Directorate and Qadisiyah University College of Pharmacy, Al-Qādisiyyah, Iraq

5 University of Basra College of Pharmacy, Basra, Iraq 